\title{
Comparative Dimensional and Microscopic Analysis of the Strength and Hardness of Internal Fixation Plates
}

\author{
Victor Tieghi Neto1, Eduardo Stedile Fiamoncini', Matheus Falsarelli Ferreira ${ }^{2}$, \\ Danilo Luiz Flumignan ${ }^{3}$, Luis Geraldo Vaz ${ }^{4}$, Eduardo Sanches Gonçales ${ }^{*}$ \\ ${ }^{1}$ Department of Stomatology, Bauru School of Dentistry, University of Sao Paulo, Bauru, Brazil \\ ${ }^{2}$ Bauru School of Dentistry, University of Sao Paulo, Bauru, Brazil \\ ${ }^{3}$ Instituto Federal de Educação, Ciência e Tecnologia de São Paulo, IFSP, Matão, Brazil \\ ${ }^{4}$ Department of Dental and Prosthetic Materials, Araraquara School of Dentistry, University of Sao Paulo, Araraquara, Brazil \\ Email: *eduardogoncales@usp.br
}

How to cite this paper: Neto, V.T., Fiamoncini, E.S., Ferreira, M.F., Flumignan, D.L., Vaz, L.G. and Gonçales, E.S. (2020) Comparative Dimensional and Microscopic Analysis of the Strength and Hardness of Internal Fixation Plates. Open Journal of Stomatology, 10, 310-320.

https://doi.org/10.4236/ojst.2020.1010029

Received: August 20, 2020

Accepted: October 27, 2020

Published: October 30, 2020

Copyright $\odot 2020$ by author(s) and Scientific Research Publishing Inc. This work is licensed under the Creative Commons Attribution International License (CC BY 4.0).

http://creativecommons.org/licenses/by/4.0/

\section{(c) (i) Open Access}

\begin{abstract}
The fixation stability achieved with the use of plates and screws in oral and maxillofacial surgery is a decisive factor in treatment success. The mechanical and structural properties of the internal fixation materials have direct influence on the dimensional stability and resistance of a fixation system, thus influencing treatment outcomes. This study proposed to analyze the dimensional and resistance patterns of titanium plates used for obtaining stable fixation in orthognathic surgery and craniofacial trauma. For this study, 30 conventional $2.0 \mathrm{~mm}$ straight four hole plates with bridge from three brands commercialized in Brazil, were subjected to macroscopic, microscopic, strength and hardness analysis. The dimensional measurements were performed using a digital caliper. Energy-dispersive X-ray spectroscopy analysis was performed by scanning electron microscopy to analyze the chemical composition of the samples. The mechanical resistance tests were performed with a universal testing machine. The samples were then submitted to Vickers hardness analysis, complying with the standards of ASTM E92. The data collected from the dimensional study was submitted to statistical analysis of the coefficient of variation, while the values obtained during the mechanical tests were analyzed by variance (ANOVA) and Tukey's test $(\mathrm{p}<0.05)$. The sample groups presented different performances in resistance, hardness, size and surface, even though they were reported to be chemically similar compounds that allowed us to conclude the plates from Group 2 were more resistant than groups 1 and 3.
\end{abstract}




\section{Keywords}

Fracture Fixation Internal, Biocompatible Materials, Compressive Strength

\section{Introduction}

The treatment of skeletal deformities has undergone major advances in recent years. In the early days of buccomaxillofacial surgery and traumatology, the treatment of patients affected by these diseases was accomplished using fixation with steel wire, dental attachments, gutters, and orthopedic techniques, associated with the use of the intermaxillary block to favor the immobilization of the bone fragments [1] [2] [3] [4].

With the advancement of the Weston-synthesis techniques, several types of materials were developed for fixation of mandibular fractures and osteotomies, and the use of plates and screws has been the current standard treatment [2] [3] [5], which reduces morbidity to the patient, possibility of installation through intraoral accesses, a lower rate of infections, possibility of a return to normal activities in a shorter period, satisfactory upper airway permeability and, mainly, reduction or absence of the need for intermaxillary block [3] [5].

Proper stabilization of the fragments is important since bone repair is influenced by the dynamic forces of mastication [6]. Thus, the composition, manipulation, and adequate adaptation of the plates and screws are factors to be considered in the stabilization of the bone segments, because of the dynamic complexity of the stomatognathic system [5] [7].

Metals such as steel, vanadium, and titanium have been used in the manufacture of fastening materials. Titanium is used both pure and associated with other metals, and its modulus of elasticity allows adequate manipulation and adaptation of plates on the bone surface [8]. Despite this, excessive manipulation of the plates is expected to cause fatigue (a decrease in the strength limit of a metal, which may occur after repeated or cyclic loading, leading to metal fracture, with forces less than its original strength ) of the material, with its consequent rupture, being able to alter the stability of the fixation system [9]. Currently, with the variety of trademarks and composition of the fixation systems, it is necessary to evaluate the performance of these materials. The objective of the present study was to perform a comparative microscopic analysis of the resistance and hardness of internal fixation plates.

\section{Material and Methods}

The research aimed to evaluate the flexural strength and hardness of the internal fixation materials through mechanical analysis by scanning electron microscopy.

The study sample consisted of 30 (thirty) $2.0 \mathrm{~mm}$ system plates, with four holes and bridge (intermediate portion without holes), divided into 3 groups, according to the manufacturer: Group 1: 10 plates of the Neoortho ${ }^{\circledR}$ brand $(\mathrm{Cu}-$ 
ritiba, PR, Brazil); Group 2: 10 Synthes ${ }^{\circledast}$ (West Chester, PA, USA) brand name plates; Group 3: 10 Engimplan (Rio Claro, SP, Brazil) brand plates. It should be noted that the plates of Group 1 were donated by a distributor of the brand in Brazil, while the plates of Group 2 were donated by the Brazilian distributor and the plates of Group 3 were purchased from a distributor company accredited by the manufacturer, through the use of resources from the São Paulo State Research Support Foundation (FAPESP) (Process number: 2011/062800), for another research project and also used for the present study.

In all plates of the 3 groups, the microscopic dimensions of the hardness and mechanical test were analyzed, as described below:

\subsection{Dimensional Analysis}

The purpose of the present analysis was to verify the standardization of the dimensions of the plates of the same manufacturer and between the manufacturers. The measurements were performed by a single examiner, according to a method modified by Brasileiro and Passeri [10], using a $150 \mathrm{~mm} / 6^{\prime \prime}$ digital caliper (Figure 1).

The measurements of each group were submitted to analysis of variation (ANOVA) and Turkey's test with the significance of $p<0.05$. Data were analyzed using the Statistical software version 7 (State Soft Inc. Tulsa, USA).

\subsection{Mechanical Testing}

The mechanical test was performed in the $\mathrm{EMIC}^{\oplus}$ universal testing machine, model DL 500, which operates in a force range between 20 and $5000 \mathrm{~N}$, with a three-point bending test method. The plates were positioned on the testing machine on two metal rollers and the force was applied by a load cell with a point incident on the center of the plate bridge. It should be noted that the testing machine performs the bending test to check the resistance by applying force and displacement of the measuring tip of the machine force. In the present study, only the plate was folded after the first application of the displacement; thus, after the first mechanical strength test, the plates were rectified and resubmitted to the same mechanical test, as described previously. The data obtained using the

1

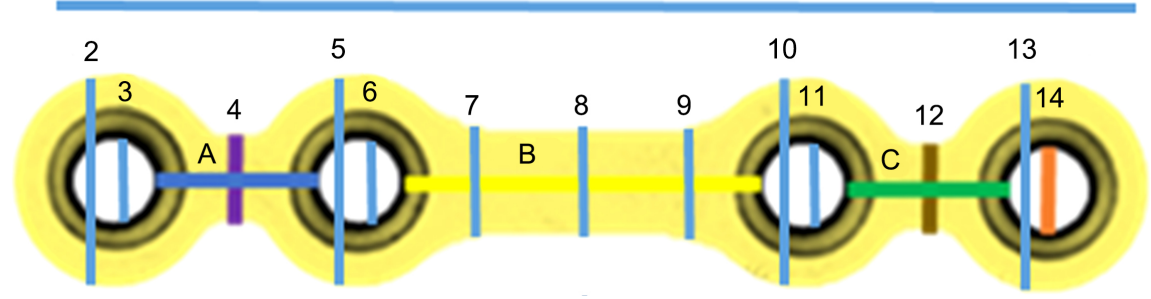

Figure 1. 1-Plate length (black). Plate width (red). Space between holes E (blue). Space between holes D (green). Bridge length (yellow). The diameter of the hole (orange). Plate width in the space between holes $\mathrm{E}$ (purple). Plate width in the space between holes $\mathrm{D}$ (brown). Plate thickness (gray). 
mechanical test were submitted to analysis of variation (ANOVA) and the $\mathrm{Tu}$ key's test with the significance of $95 \%(\mathrm{p}<0.05)$, according to the studies of Trivellato, Mazzonetto, Passeri and Consani [11], and Brasileiro, Grempel, Ambrosano and Passeri [12]. Data were analyzed using the Statistical software version 7 (State Soft Inc. Tulsa, USA).

\subsection{Hardness Analysis (Vickers Hardness Test)}

The plates were fixed (with Godiva) on a circular base of acrylic resin; after placing the test piece in the device (MicroMet 6040), the choice of placement was made to make the measurements through objective lenses with 10 and $50 \mathrm{x}$ magnification. The apparatus was calibrated with a load of $500 \mathrm{~N}$ and time of 10 seconds and the Vickers tip was selected. The computer program captures the image of the location where the indenter was printed (diamond-shaped) of the penetrator in the specimen, making it possible to measure the diagonals of the polygon to obtain the values of the test (HV) (Figure 2). The place of choice for application of the test was the corresponding area between holes at one end of the plate. Each test specimen was submitted to the hardness test at three different points, with a distance of $5 \mathrm{~mm}$ between them, where the established value was obtained through the average of these 3 points.

\subsection{Microscopic Analysis}

The plates were subjected to scanning electron microscopy (Scanning Electron Microscope JSM-T220A, JEOL Ltd, Tokyo, Japan), in a 1000-fold increase in order to verify the components thereof, by reading the EDS (Energy-dispersive $\mathrm{X}$-ray spectroscopy analysis) as well as for analysis of its surface structure.

\section{Results}

\subsection{Dimensional Analysis}

The analysis of dimensional standardization showed a statistically significant difference for all groups analyzed. The data related to the dimensional analysis are shown in Table 1.

\subsection{Mechanical Testing}

The results indicate that there was a statistically significant difference $(\mathrm{p}<0.05)$ between the three groups when analyzed by the ANOVA test and that there were

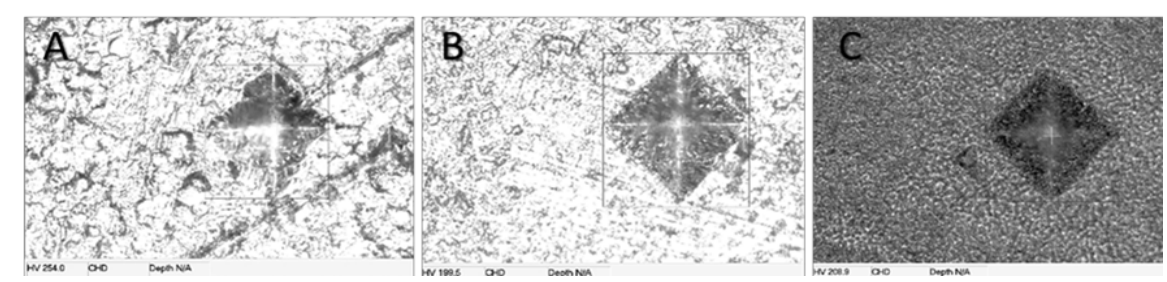

Figure 2. Evaluation of the edentation by scanning microscopy for the Vickers hardness test: A-Group 1, B-Group 2, C-Group 3. 
Table 1. Means and their respective standard deviations of the measurements of the plates. Analysis of variance between groups and the significance of ANOVA and Tukey's tests.

\begin{tabular}{|c|c|c|c|c|}
\hline \multirow{2}{*}{ Medidas } & \multicolumn{3}{|c|}{ MÉDIAS } & \multirow{2}{*}{$\mathrm{P}<0.05$} \\
\hline & Grupo 1 & Grupo 2 & Grupo 3 & \\
\hline $\mathrm{CT}$ & 29.741 & 27.91 & 30.488 & All groups \\
\hline LF1D & 4.454 & 4.98 & 5.344 & All groups \\
\hline LF2D & 4.426 & 4.98 & 5.337 & All groups \\
\hline LF1E & 4.434 & 4.97 & 5.368 & All groups \\
\hline LF2E & 4.407 & 4.97 & 5.364 & All groups \\
\hline LFD & 1.868 & 2.03 & 2.814 & All groups \\
\hline LFE & 1.843 & 2.02 & 2.804 & All groups \\
\hline LPFD & 2.367 & 2.5 & 2.819 & All groups \\
\hline LP & 2.312 & 2.5 & 2.811 & All groups \\
\hline LPFE & 2.308 & 2.49 & 2.817 & All groups \\
\hline EFD & 2.116 & 3.94 & 4.239 & All groups \\
\hline EFE & 2.063 & 3.95 & 4.214 & All groups \\
\hline $\mathrm{CP}$ & 8.209 & 8.94 & 10.023 & All groups \\
\hline DF1D & 1.994 & 2.01 & 2.079 & G1 e G3/G2 e G3 \\
\hline DF2D & 2.011 & 2.01 & 2.081 & G1 e G3/G2 e G3 \\
\hline DF1E & 2.006 & 2.02 & 2.089 & G1 e G3/G2 e G3 \\
\hline $\mathrm{DF} 2 \mathrm{E}$ & 2.006 & 2.02 & 2.071 & G1 e G3/G2 e G3 \\
\hline EspF1D & 0.907 & 1.01 & 0.983 & G1 e G2/G1 e G3 \\
\hline EspF2D & 0.923 & 1 & 0.957 & G1 e G2 \\
\hline EspFD & 0.919 & 1 & 0.952 & G1 e G2 \\
\hline EspPD & 0.923 & 1 & 0.966 & Não Significante $(P>0.05)$ \\
\hline EspCP & 0.875 & 1 & 0.97 & G1 e G2/G1 e G3 \\
\hline EspPE & 0.922 & 1 & 0.969 & G2 e G3 \\
\hline EspF1E & 0.932 & 1 & 0.956 & G1 e G3 \\
\hline EspF2E & 0.923 & 1 & 0.957 & G1 e G3 \\
\hline EspFE & 0.864 & 1 & 0.959 & G2 e G3 \\
\hline
\end{tabular}

Legend: CT-Total length of the plate, LF1D-Width of the holes 1D, LF2D-Width of the holes 2D, LF1E-Width of the holes 1E, LF2E-Width of the holes 2E, LFD-LFE-Width region between holes E, LPFD—Width intermediate region/bridge hole D, LP —Width intermediate region/center bridge, LPFEWidth intermediate region/bridge hole E, EFD-Space between holes D, EFE-Space between holes E, CP-Bridge length, DF1D-Diameter of hole 1D, DF2D-Diameter of hole 2D, DF1E-Diameter of hole 1E, DF2E-Diameter of hole 2E, EspF1D-Plate thickness over hole 1D, EspF2D-Plate thickness on thickness 2D, EspFD-Thickness of the plate between holes D, EspPD-Thickness of the bridge plate at $\mathrm{D}$, EspCP-Thickness of the bridge center plate, EspPE-Thickness of the bridge plate at E, EspF1E-Thickness of the plate on hole $1 \mathrm{E}$, EspF2E-Plate thickness over hole 2E, EspFE-Plate thickness between holes E. 
intra-group differences between the first and second stages between Groups 2 and 3, that is, Group 2 presented higher mechanical resistance when compared to Groups 1 and 3. Table 2 shows the mean values obtained in the mechanical test, as well as the results of the statistical tests used (ANOVA and Tukey's p < 0.05 ), while Graph 1 shows the relationship of resistance comparing between the three groups.

\subsection{Vickers Hardness Analysis}

In general, it was observed that the plates of Group 2 were harder than those of the other groups. Table 3 shows the values for the total mean of each group.

\subsection{Analysis of Electronic Microscopy and EDS}

The analysis of the electron microscopy showed that the three groups present different aspects of surface finishing when viewed with 1000x increase (Figure 3).

EDS showed that the plates of the three groups studied had a similar composition, being composed basically of commercially pure titanium (Ti 98\%) Grade 1. The plates of Group 3 contained phosphorus particles in their composition and the aluminum detected in the reading took place of the support that sustained the samples and were not relevant to the study. The analyses are represented in Graph 2, Graph 3, and Graph 4.

Table 2. Mean values of the mechanical test, in Newtons, standard deviation (S), difference between F2 and F1 and test results of intra and intergroup variance (ANOVA) and Tukey's test $(\mathrm{p}<0.05)$.

\begin{tabular}{cccc}
\hline & F1 (S) & F2 (S) & F2-F1 \\
\hline Group 1 & $16.05(0.41)$ & $16.42(0.47)$ & $0.37^{\star}$ \\
Group 2 & $23.6(0.33)$ & $24.92(0.31)$ & 1.32 \\
Group 3 & $17.03(0.34)$ & $17.9(0.30)$ & 0.87
\end{tabular}

Legend: F1 = force in the first measurement; F2 = force in the second measurement. ${ }^{\star}=$ not significant in the intragroup evaluation.

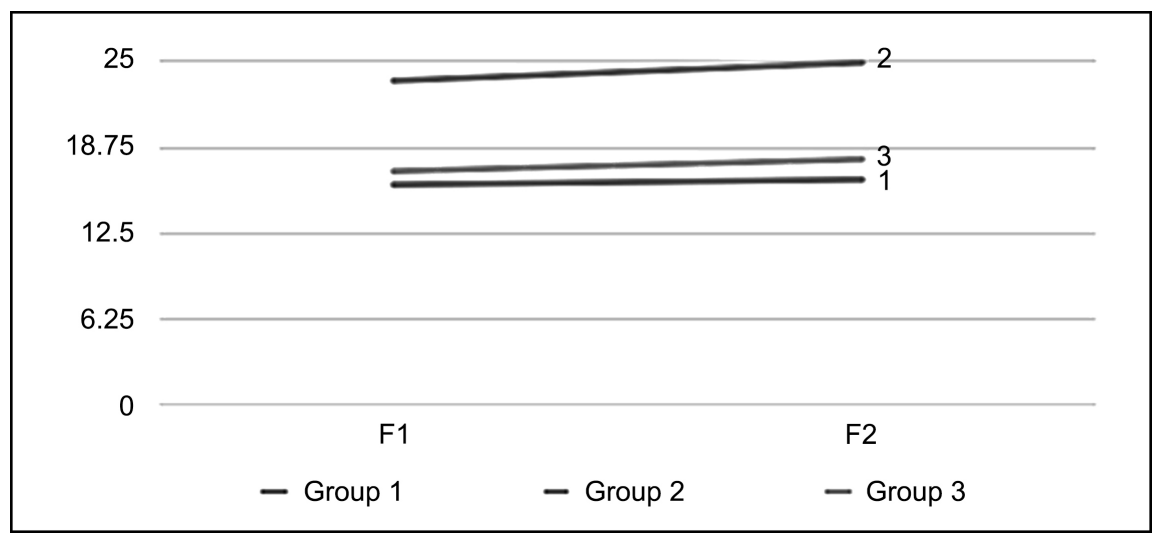

Graph 1. Measurement of the loads obtained during the flexion test. F1 = first test; F2 = second test after manual rectification of the plate. 
Table 3. Mean and standard deviation (SD) of Vickers hardness (HV) and statistical significance. $S$ = significant $(\mathrm{p}<0.05)$.

\begin{tabular}{ccc}
\hline Grupos & Média (DP) & Significância \\
\hline 1 & $199.39(3.32)$ & $\mathrm{S}$ \\
2 & $251.31(2.88)$ & $\mathrm{S}$ \\
3 & $202.62(2.66)$ & $\mathrm{S}$ \\
\hline
\end{tabular}

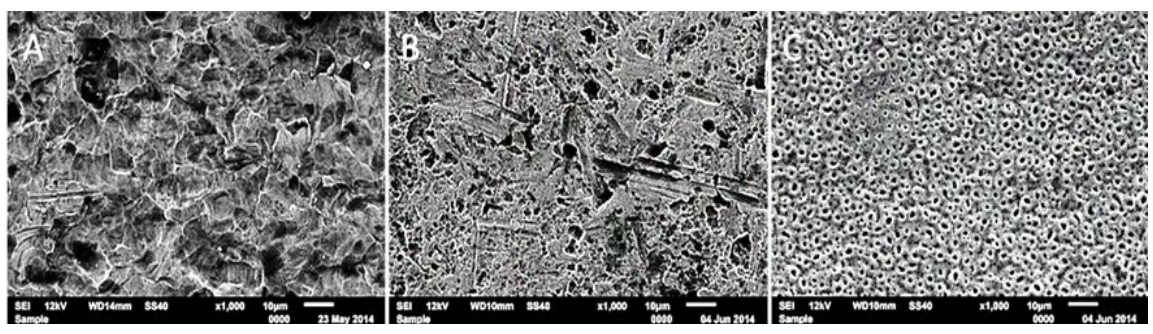

Figure 3. Evaluation of the surface of the material by electron microscopy: A-Group 1, B-Group 2, and C-Group 3.

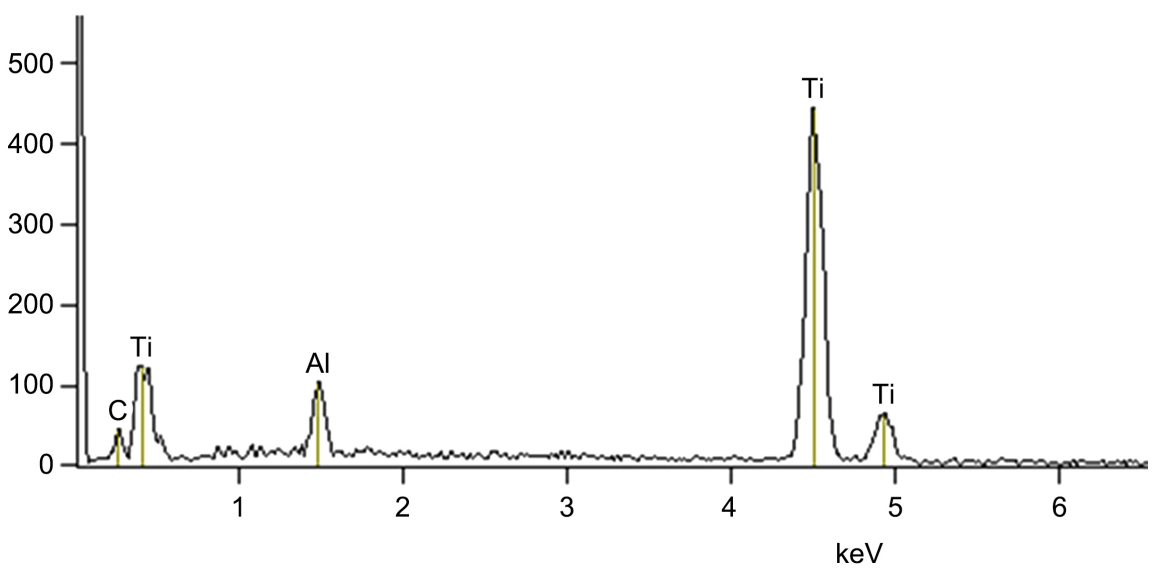

Graph 2. Surface composition of Group 1 plates.

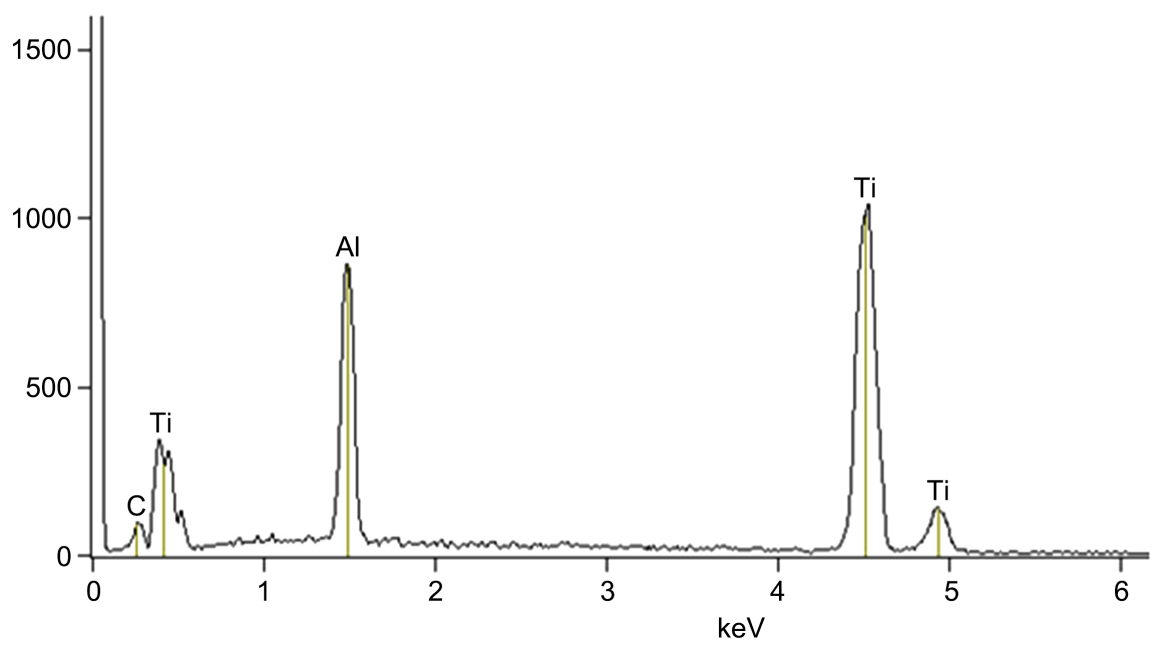

Graph 3. Surface composition of Group 2 plates. 


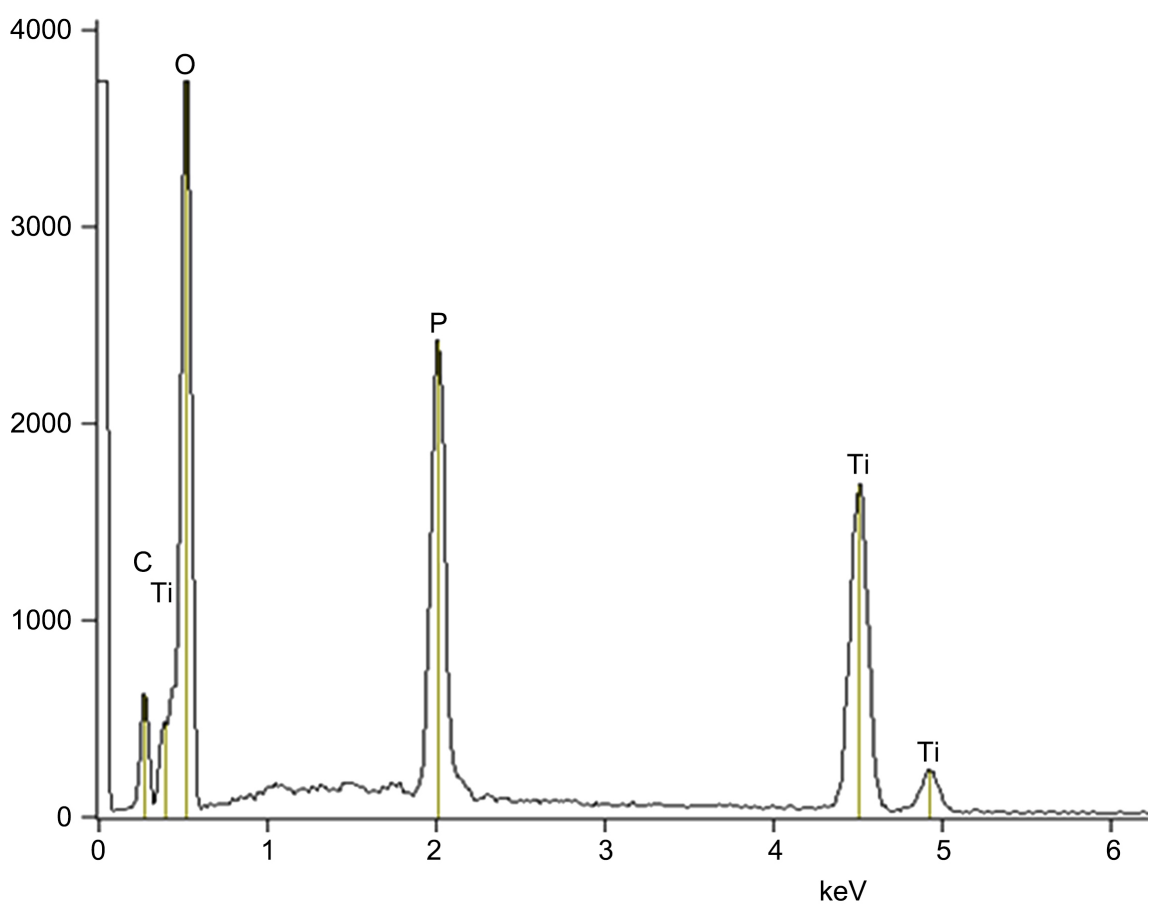

Graph 4. Surface composition of Group 3 plates.

\section{Discussion}

It is known that for the repair of bone fractures and osteotomies, adequate immobilization of the fragments is essential. In Buccomaxillofacial Surgery and Traumatology, the use of plate and screw systems has been the method of elective fixation for the treatment of face fractures and for the immobilization of bone fragments after osteotomies. There is a great diversity of fixation systems today; these, vary not only the dimensions of their plates and screws, but also their designs and constituents.

The present study was born from the impression, during use, that some plates were softer than others, since they seemed to more easily allow the folds necessary to adapt them to the bone tissue. Such adaptation may interfere with the mechanical resistance of the plates [13]. Therefore, one of the objectives was to evaluate the mechanical strength of 3 plate systems, $2.0 \mathrm{~mm}$. Obviously, the dimensions of the fixation system employed influence both the execution of folds for adaptation and the immobilization of the bone. We chose to use $2.0 \mathrm{~mm}$ system plates, with intermediate (bridge) and 4 holes, which are plates widely employed in the fixation of mandibular osteotomies. It should be noted that, in this context, the standardization of the dimensions of the plates has to be verified.

Therefore, before carrying out the study of the resistance of the plates, the dimensional analysis of the plates was carried out to verify if plates of different manufacturers, all of the $2.0 \mathrm{~mm}$ system, had the same dimensions, since dimensional differences of the systems can influence the mechanical test [9]. The results of the present study are in agreement with other studies [9] [11], which verified that there are dimensional differences between the plates of different 
manufacturers and that this seems to be more critical for the plates manufactured in Brazil (Groups 1 and 2 of the present study). Although statistically significant, the observed differences were small between the plates of Groups 1 and 2 ; the plates of Group 3 presented greater dimensional difference.

Despite the above, in the present study, this difference did not seem to have influenced the mechanical resistance, since the analysis of flexion of the plates of Group 3 were less resistant than those of Group 2, and more resistant than that of Group 1. It is worth noting that the plates of Group 2 showed lower variability among their dimensions, besides being smaller than those of Group 3, and presented the highest mechanical resistance among the 3 groups studied. The results of the flexion test (mechanical resistance test of the present study, according to the study by Rocha Júnior et al. [9], who also tested plates of the same brands of the plates of Groups 1 and 2, and with Trivellato et al. [11] who observed higher values (in the present study), when compared to the values of the Group 3 plate flexion test (from the present study). It should be emphasized that the study by Trivellato et al. [11] evaluated, among others, the same plates of Groups 2 and 3 of the present study.

The hardness of a material can be translated by the penetration resistance of its surface. The Vickers hardness is based on the resistance the material offers to the penetration of a square-shaped diamond pyramid and the angle between faces of $136^{\circ}$ under a given load. The Vickers hardness value (HV) is the quotient of the applied load (F) by the printing area (A) left on the body tested. The study by Matthew et al. [14] compared the Vickers hardness of titanium plates and stainless steel, which validates the method for Vickers plate hardness verification; besides, their results showed Vickers hardness difference between the studied plates, which corroborates the importance of the components of the plate about its hardness. It seems logical to believe that harder plates, that is, with greater Vickers hardness, are more resistant and possibly result in a more stable fixation. Also, because they are harder, they can become more difficult to bend and adapt to the bone. In the present study, the plates of Group 2 showed Vickers hardness superior to the plates of Groups 1 and 3, this being a factor that contributed for the increased resistance of the plates of this group, even being dimensionally smaller, when compared with those of Group 3, for example. This fact may be due to its composition, even though it is more similar to the composition of the plates of Group 1. If the plates are of similar composition, perhaps the manufacturing process is responsible for the hardness difference. We lack data to deepen the discussion in this regard.

The values obtained in the evaluation of mechanical strength can be attributed to the design, standardization of dimensions, and constituent material. Thus, the higher mechanical resistance of plates of different sizes may be due to differences between the constituent components of the plates [15] [16]. The energy dispersive spectrometry (EDS) performed in the present study qualitatively showed the chemical elements of the surface of the plates. The present study is in agreement 
with Trivellato et al. [11], because, in a similar way to the authors mentioned above, the presence of commercially pure titanium was verified, classified as grade 1 , in all plates evaluated, however, phosphorus and oxygen ions were found in Group 3; it is worth noting that the study by Trivellato et al. [11] evaluated plates of markings corresponding to Groups 2 and 3 of the present study. On the other hand, Rocha Júnior et al. [9], evidenced the presence of pure titanium in the samples of the same manufacturers of Groups 1 and 2 of the present study, plus sodium, phosphorus, sulfur, potassium, chlorine, carbon, nitrogen, aluminum, silicon and calcium, iron, zinc, phosphorus, potassium, nickel, and nitrogen (on the plates of Group 2 of the present study).

The presence of aluminum observed in the SDS of Groups 1 and 2 of the present study may be due to external contamination, specifically the tip of the universal testing machine. Thus, since the constituent components of the three groups are basically the same, the discrete differences found do not seem to be responsible for the differences in the results of the mechanical tests. Perhaps the manufacturing process may have some interference in this, but we lack data to discuss this process, since the manufacturers usually keep secrecy of their processes or part of them.

\section{Conclusion}

It was concluded that, although the studied systems presented similar compounds, it was possible to observe different behaviors in terms of size, strength, hardness, and surface characteristics. The plates of Group 2 presented a superior performance about the dimensional analysis and the tests of strength and hardness, indicating that it can present greater stability to the bone fragments fixed with it. We also consider that the clinical applicability of the results varies according to the level of professional experience, relating in large part according to the number of movements performed during the manipulation of the material. Thus, it is observed that no material has excellent characteristics in all necessary aspects, and it is necessary to evaluate the favorable points that bring the expected benefits to the needs of the patient and the surgeon.

\section{Conflicts of Interest}

The authors declare no conflicts of interest regarding the publication of this paper.

\section{References}

[1] Michelet, F.X., Deymes, J. and Dessus, B. (1973) Osteosynthesis with Miniaturized Screwed Plates in Maxillo-Facial Surgery. Journal of Maxillofacial Surgery, 1, 79-84. https://doi.org/10.1016/S0301-0503(73)80017-7

[2] Ellis, E. (1993) Rigid Skeletal Fixation of Fractures. Journal of Oral and Maxillofacial Surgery, 51, 163-173. https://doi.org/10.1016/S0278-2391(10)80016-3

[3] Obwegeser, H.L. (2007) Orthognathic Surgery and a Tale of How Three Procedures Came to Be: A Letter to the Next Generations of Surgeons. Clinics in Plastic Sur- 
gery, 34, 331-355. https://doi.org/10.1016/j.cps.2007.05.014

[4] Ellis III, E. (2014) An Algorithm for the Treatment of Noncondylar Mandibular Fractures. Journal of Oral and Maxillofacial Surgery, 72, 939-949. https://doi.org/10.1016/j.joms.2013.11.026

[5] Al-Moraissi, E.A. and Ellis, E. (2014) What Method for Management of Unilateral Mandibular Angle Fractures Has the Lowest Rate of Postoperative Complications? A systematic Review and Meta-Analysis. Journal of Oral and Maxillofacial Surgery, 72, 2197-2211. https://doi.org/10.1016/j.joms.2014.05.023

[6] Feller, K.U.G., Richter, M. and Schneider, U. (2002) Combination of Microplate and Miniplate for Osteosynthesis of Mandibular Fractures: An Experimental Study. International Journal of Oral and Maxillofacial Surgery, 31, 78-83. https://doi.org/10.1054/ijom.2000.0182

[7] Ellis III, E. and Esmail, N. (2009) Malocclusions Resulting from Loss of Fixation after Sagittal Split Ramus Osteotomies. Journal of Oral and Maxillofacial Surgery, 67, 2528-2533. https://doi.org/10.1016/j.joms.2009.06.022

[8] Roig, M.A. (2002) Valoración a largo plazo de los resultados de tratamiento mediante osteosíntesis con miniplacas en sus diferentes usos en cirugía craneomaxilofacial. Tese (Doutorado em Cirurgia e Medicina)_Facultat de Medicina, Barcelona, $138 \mathrm{p}$.

[9] Rocha Júnior, H.V., Padovan, L.E.M., Oliveira, R.B., Assis, D.S.F.R. and Duarte, M.A.H. (2013) Avaliação ultraestrutural,dimendional e mecânica de dois sistemas de fixação interna rígida de 2mm. Revista Salusvita, 32, 125-137.

[10] Brasileiro, B.F. and Passeri, L.A. (2008) Avaliação dimensional de miniplacas e parafusos para cirurgia ortognática. Revista Brasileira de Cirurgia e Traumatologia, 5, 51-56.

[11] Trivellato, A.E., Mazzonetto, R., Passeri, L.A. and Consani, S. (2000) Estudo químico, macroscópico e da resistência à flexão de placas e parafusos de titânio usados na fixação interna rígida. Pesquisa Odontológica Brasileira, 14, 392-398. https://doi.org/10.1590/S1517-74912000000400015

[12] Brasileiro, B.F., Grempel, R.G., Ambrosano, G.M.B. and Passeri, L.A. (2009) An in Vitro Evaluation of Rigid Internal Fixation Techniques for Sagittal Split Ramus Osteotomies: Advancement Surgery. Journal of Oral and Maxillofacial Surgery, 67, 809-817. https://doi.org/10.1016/j.joms.2008.11.009

[13] Haug, R.H., Street, C.C. and Goltz, M. (2002) Does Plate Adaptation Affect Stability? A Biomechanical Comparison of Locking and Nonlocking Plates. Journal of Oral and Maxillofacial Surgery, 60, 1319-1326.

https://doi.org/10.1053/joms.2002.35732

[14] Matthew, I.R., Frame, J.W., Browne, R.M. and Millar, B.G. (1996) In Vivo Surface Analysis of Titanium and Stainless Steel Miniplates and Screws. International Journal of Oral and Maxillofacial Surgery, 25, 463-468. https://doi.org/10.1016/S0901-5027(96)80085-3

[15] De Oliveira, K.P., De Moraes, P.H., Da Silva, J.S.P., De Queiroz, W.F. and Germano, A.R. (2014) In Vitro Mechanical Assessment of 2.0-mm System Three-Dimensional Miniplates in Anterior Mandibular Fractures. International Journal of Oral and Maxillofacial Surgery, 43, 564-571. https://doi.org/10.1016/j.ijom.2013.10.008

[16] Kunčická, K., Kocich, R. and Lowe, T.C. (2017) Advances in Metals and Alloys for Joint Replacement. Progress in Materials Science, 88, 232-280.

https://doi.org/10.1016/i.pmatsci.2017.04.002 